\title{
Actinic granuloma
}

\author{
Reza Yaghoob ${ }^{1}$, Nastaran Ranjbari², Amir Feily ${ }^{3}$
}

1 Department of Dermatology, Jundishapur University of Medical Sciences, Ahvaz, Iran

2 Department of Pathology, Jundishapur University of Medical Sciences, Ahvaz, Iran

3 Department of Dermatology, Jahrom University of Medical Sciences, Jahrom, Iran

Keywords: actinic granuloma, elastin fiber

Citation: Yaghoob R, Ranjbari N, Feily A. Actinic granuloma. Dermatol Pract Concept. 2014;4(3):4. http://dx.doi.org/10.5826/ dpc.0403a04

Received: April 1, 2014; Accepted: June 5, 2014; Published: July 31, 2014

Copyright: $\odot 2014$ Yaghoob et al. This is an open-access article distributed under the terms of the Creative Commons Attribution License, which permits unrestricted use, distribution, and reproduction in any medium, provided the original author and source are credited.

Funding: None.

Competing interests: The authors have no conflicts of interest to disclose.

All authors have contributed significantly to this publication.

Corresponding author: Amir Feily, Department of Dermatology, Honari Clinic, Motahari St, Jahrom, Iran. Tel. ++ 989177204638. Email: dr.feily@yahoo.com

Actinic granuloma is a rare, idiopathic disorder of middleaged adults that always appears in sun-exposed skin [1,2]. It is a form of granulomatous dermatosis characterized by annular plaques with central atrophy and raised erythematous margins that are similar to those observed in granuloma annulare (GA) [3].

A 42-year-old man presented with a three-month history of an asymptomatic erythematous annular and serpiginous lesion on his forehead. There was no history of preceding trauma to the area. He was not on any medications. Examination revealed an erythematous to brown annular to serpiginous plaque with central atrophy (Figure 1). Systemic examination revealed no abnormalities. Results of full blood count and multiple biochemical analyses were unremarkable.

Skin biopsy showed normal epidermis with significant solar elastosis and granulomatous reaction in dermis, composed of numerous multinucleated giant cells. There was no area of necrobiosis. Verhoeff von Gieson stained sections revealed loss of elastic fiber in the center but the presence of fragments of elastin within the giant cells (Figure 2). Alcian blue staining was negative of mucin (Figure 3).

O'Brien's actinic granuloma is a chronic disease that affects middle-aged individuals of either sex who have a history of intense sun exposure [3]. It begins as small skin-

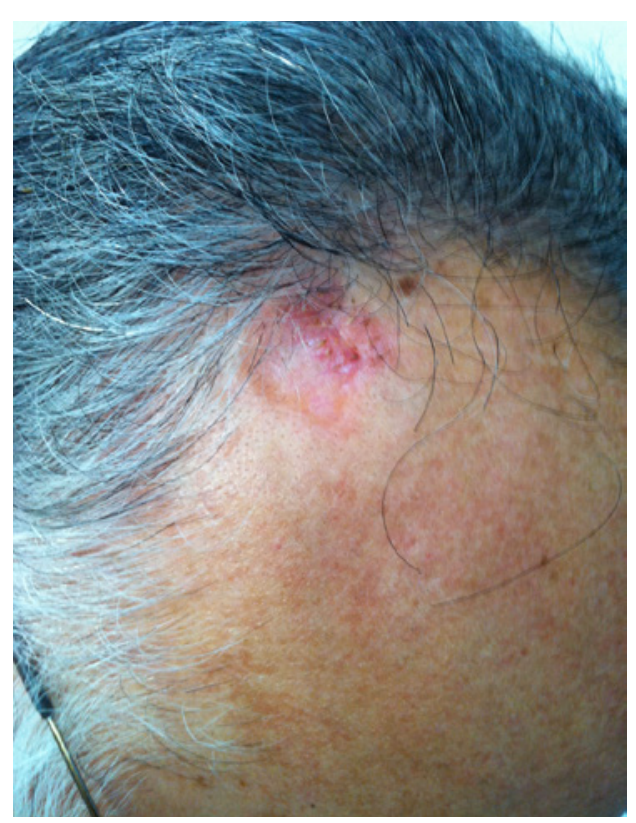

Figure 1. Erythematous to brown annular-like plaque with signs of atrophy at the center. [Copyright: (92014 Yaghoob et al.]

colored or pink papules that quickly evolve into annular plaques. The border of the lesion extends slowly at the periphery while the center returns to a slightly atrophic appearance 


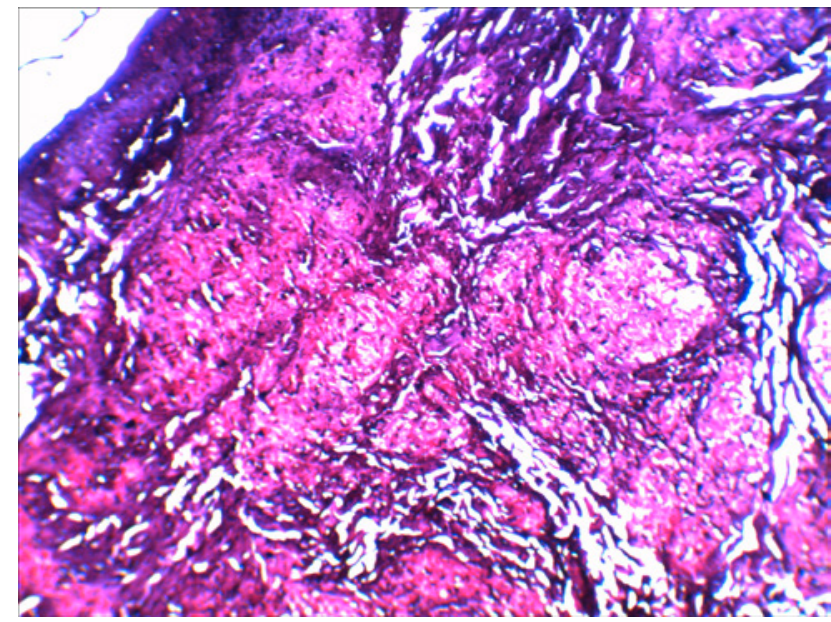

Figure 2. Verhoeff von Gieson stained sections revealed loss of elastic fiber in the center but presence of fragments of elastin within the giant cells. [Copyright: (O2014 Yaghoob et al.]

[1]. The pathogenesis of the condition is unknown; however, solar elastosis of sun damage is believed to be a triggering factor [1,3]. It is also reported in association with prolonged doxycycline [4]. O’Brien, who initially described actinic granuloma in 1975 postulated that actinic damaged elastic fibers are the antigenic stimuli that trigger the inflammatory process leading to reparation of sun damaged connective tissue $[5,6]$. Annular elastolytic giant cell granuloma (AEGCG) was proposed by Henke et al. and used to describe a clinically and histologically similar cutaneous eruption not limited to sun exposure and without solar elastosis [6]. These two conditions may represent a single diagnostic entity and have been grouped under the title "granular elastolytic giant cell granuloma" and proposed as a diagnosis for all annular lesions exhibiting a zonal histologic pattern that includes a granulomatous response with giant cells at the annular rim and centrally a loss of elastic fibers or solar elastotic material [7]. Clinical differentials include facial lesions of granuloma annulare, necrobiosis lipoidica and annular sarcoid. These can be distinguished readily on histopathological features $[8,9]$.

The characteristic histopathologic feature of actinic granuloma is multinucleated foreign body giant cells, which phagocytize the degenerated elastic fibers, a process known as elastophagocytosis. There is an absence of necrobiosis, such as facial necrobiosis lipoidica, or mucinosis, such as GA or sarcoid-like granuloma in the dermis at the solar elastosis level $[1,3]$.

Several forms of treatment with varying results have been reported, such as with chloroquine, cyclosporine, intralesional steroids, cryotherapy, methotrexate, isotretinoin, acitretin, pentoxiphylline, and retinoid psoralen + UVA (RePUVA) [3,10]. Spontaneous remission has been reported in some cases [3].

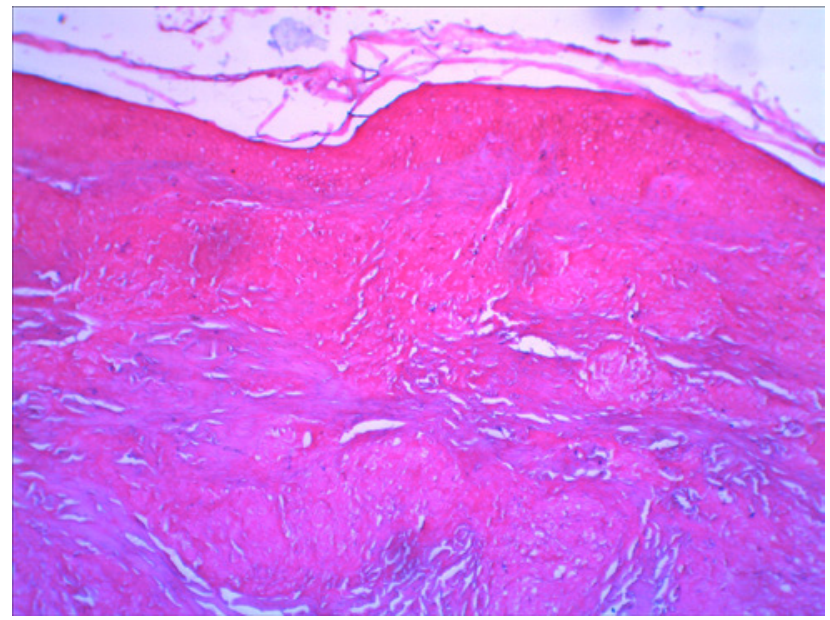

Figure 3. Alcian blue staining was negative for mucinosis. [Copyright: (C2014 Yaghoob et al.]

We report the present case of actinic granuloma because this condition is extremely rare, and patients often do not complain of it. Consequently, any instances may not be brought to medical attention. Our patient was advised to strictly sun protect. He was lost to follow up.

\section{References}

1. Gutierrez-Gonzalez E, Gomez-Bernal S, Alvarez-Perez A, SanchezAguilar D, Toribio J. Elastolytic giant cell granuloma: clinic-pathologic review of twenty cases. Dermatol Online J. 2013;19(10):3. http://escholarship.org/uc/item/80q2b8gb. Accessed June 5, 2014.

2. Le Corre Y, Steff M, Prophette B, Celerier P, Maillard H. Annular elastolytic giant-cell granuloma. Ann Dermatol Venereol. 2010;137-532-5.

3. Lazzarini R, Rotter A, Farias DC, Muller H. O’Brien's actinic granuloma: an unusually extensive presentation. An Bras Dermatol. 2011;86:339-42.

4. Lim DS, Triscott J. O'Brien's actinic granuloma in association with prolonged doxycycline phototoxicity. Australas J Dermatol. 2003;442:67-70.

5. O'Brien JP. Actinic granuloma. An annular connective tissue disorder affecting sun and heat damaged (elastotic) skin. Arch Dermatol. 1975;111:460-6.

6. Wang C-Y, Pujol RM, Lee W-H, Su W-P. Annular elastolytic granuloma: a clinicopathologic study of 15 cases and a literature review. Dermatol-Sinica. 1996;14:51-64.

7. Weedon D. Elastolytic granulomas. In: Weedon D. Weedon's Skin Pathology, 3rd ed. London: Churchill-Livingstone, 2010:188-9.

8. Tee SL, Chen QP, Lim YL. Necrobiosis lipoidica with elastophagocytosis on an unusual location. Am J Dermatopathol. 2014 Apr 28 [Epub ahead of print].

9. Kumari R, Thappa DM, Chougule A, Adityan B. Granuloma multiforme: a report from India. Indian J Dermatol Venereol Leprol. 2009;75_296-9.

10. Stefanaki C, Panagiotopoulos A, Kostakis P, Stefanaki K, Petridis A. Actinic granuloma successfully treated with acitretin. Int J Dermatol. 2005;44:163-6. 